\title{
Experimental Study on Heat Alteration of Palaeolithic Material: Preliminary Results from Shale in the Northeastern Region of Japan
}

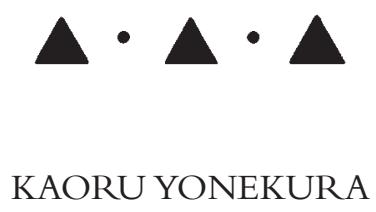

INTRODUCTION

Since CRABTRee AND BUtLer PRESENTEd a Detailed Discussion of the heat treatment of lithic materials in their pioneering work (1964), several researchers have investigated the intentional thermal alteration (i.e., heat treatment or annealing) of prehistoric rocks (Mandeville 1973). In particular, it has been reported that the flakeability and surface morphology of microcrystalline and cryptocrystalline siliceous rocks can be changed effectively by well-controlled heating (Crabtree and Butler 1964).

When the present author was working on shale artifacts obtained from a Palaeolithic site called the Ueno-A site (Yonekura and Abe 2002) in the northeastern region of Japan, some artifacts were found to exhibit heat traces such as color alterations and fracture surfaces, including "potlids," caused by thermal damage. These observations led to the question of whether Palaeolithic toolmakers at this site had devised techniques for the thermal alteration of rocks.

In this study, in order to examine whether it is reasonable to assume that Palaeolithic toolmakers intentionally heat-treated rocks at this site, controlled heating experiments were performed on some shale samples. Functional change in shale due to heat treatment was assessed, and its possible influence on manufacturing processes and completed tool performance was examined.

HEAT TRACES IN AN ARCHAEOLOGICAL SAMPLE

The Ueno-A site is located on a river terrace overlooking the Oh-irima and Sagae Rivers in Yamagata prefecture in the northeastern region of Japan (Fig. 1). Flaked tools $(73,433)$ were obtained from five excavations at this site; among these, more than 99 percent of the flaked artifacts were petrologically identified as shale. Other types of remains such as food and features were not discovered in this site.

Although shale is generally defined as a fine-grained laminated or fissile sedimentary rock made up of silt- and clay-sized particles, its mineral composition, particuKaoru Yonekura is a research assistant in Composite Material Group, Hybrid Materials Center, National Institute for Materials Science, Japan. 


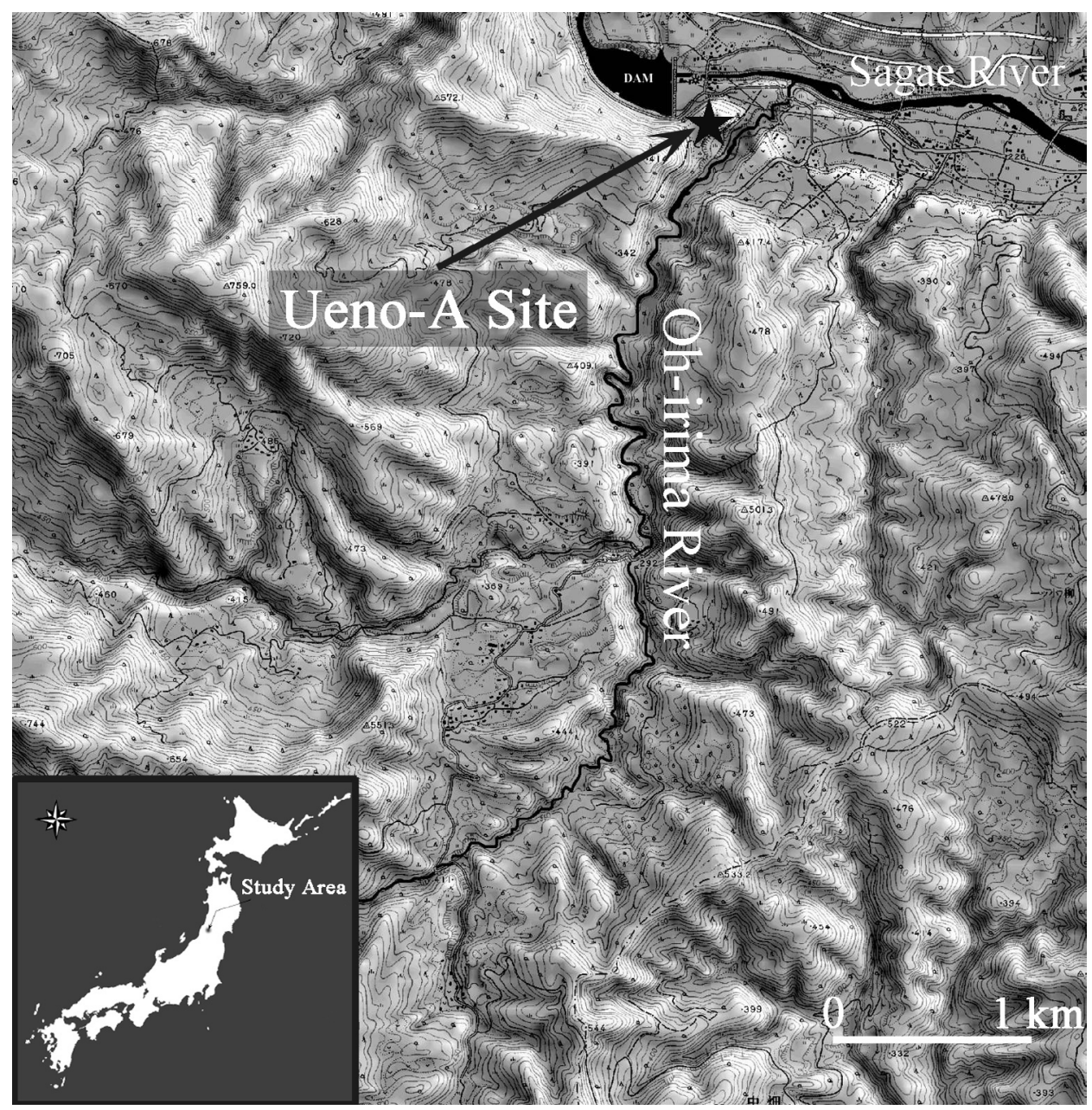

Fig. 1. The study area indicating the location of the site. The Ueno-A site is located on a river terrace overlooking the Oh-irima and Sagae Rivers in Yamagata prefecture in the northeastern region of Japan.

larly the silica content, has been reported to vary widely (Siever 1978; Yaalon 1962). In our previous work, it was demonstrated that only homogeneous shale materials having a very high content of $\alpha$-quartz were intentionally selected for manufacturing Palaeolithic tools at this site (Yonekura et al. 2008).

In this area, the "Kusanagi Formation" has large amounts of shale in the form of boulders and bedrock (Taguchi et al. 1986). Additionally, near the site, the Tsukinuno mudstone layer that is comparable to the Kusanagi Formation covers a wide area. The Oh-irima River flows through this layer in the immediate vicinity of the site. Since it is possible to obtain large shale rocks from among the various types of rock in the riverbed of the Oh-irima River, it has been speculated that the materials used for manufacturing tools at the site were collected from locations adjacent to the site, especially from the riverbed. This supposition is supported by the fact that some materials used for manufacturing tools at the site could be restored to the state of nodules 
through refitting procedures, and these exhibited shape and size characteristics similar to those of nodules currently found in the riverbed.

Patterned stone implements obtained from the site included morphologically standardized medium-sized blades; backed blades, gravers, and scrapers made from the blades were also obtained. Additionally, many bifacial points were found at the site. The fact that more than 99 percent of the artifacts were comprised of small debris that might have been a by-product of tool manufacture implies that highly intensive manufacturing activities were performed at this site.

Although reliable ${ }^{14} \mathrm{C}$ data was not obtained, based on the patterned-type tools and the Paleolithic chronology in Japan, this site was dated to the late Upper Pleistocene. Because these artifacts were quite densely and uniformly packed in one thin layer, it was difficult to divide the assemblage on the basis of stratigraphical characteristics.

All of the artifacts obtained in this site were stone tools and the details of archaeological context have not been fully solved. However, our previous study pointed out that the manner of material selection and utilization in this site was very elaborate and toolmakers had the ability to select suitable materials for certain type of tools (Yonekura et al. 2008). In this study, further material utilization is examined, particularly focusing on the heat alteration techniques on rock materials.

As mentioned above, heat traces such as surface color alterations, extremely rough and uneven fracture surfaces that were occasionally observed on "overheated" rocks, and potlid fractures had been found on several artifacts obtained from the excavations. The traces of heat effects were carefully examined on 8848 major artifacts, excluding small debris obtained from sieving processes. The study focused on the following features: (1) alteration in surface texture and formation of rough surfaces such as crenated fractures and potlids; and (2) color alterations from white/gray/brown to pink/ red, and occasionally to black/gray.

The alteration of surface texture, including the formation of potlids, is occasionally considered to be undesired thermal damage (Patterson 1995a), and these features do not necessarily indicate intentional heat treatment of rocks (Patterson 1995b; Rondeau 1995). However, it has been reported that "where heat treatment has occurred, it is often possible to find some specimens of debitage that possess at least small potlid fracture scars" (Patterson 1995a), and there was no solid evidence to support the existence of natural heat effect in this site. Hence, the alteration of surface texture was added to the criteria.

A glossy, vitreous surface — called luster-was also observed on several artifacts; however, it has been reported that the luster on siliceous rocks caused by heat was occasionally confused with silica sheen (Rowney and White 1997), and this feature does not always occur during heating. Therefore, this factor was excluded from the criteria considered in this study.

As a result of the observations, surface change and color alteration were recognized in a number of artifacts. Among the 8848 artifacts, 214 (2.4\%) exhibited surface texture alterations, and $104(1.2 \%)$ shale artifacts exhibited color alterations. Some of them exhibited intense color alterations and morphological change.

On the basis of this preliminary result, and in order to examine the possibility of intentional heat treatment of Palaeolithic shale materials at this site as one of the techniques employed by Palaeolithic toolmakers, a heating experiment was performed in laboratory conditions on some shale samples. In order to quantitatively assess the alteration of material properties by heat treatment that could have influenced the man- 
ufacturing process and performance of completed tools, the mechanical properties as well as the surface morphologies of shale samples that were obtained adjacent to the site were analyzed.

\section{EXPERIMENTAL SETTINGS AND ANALYTICAL METHODS}

\section{Sample Preparation and Experimental Settings}

Shale samples used for the experiments were collected from the local channel of the Oh-irima River since it was considered a potential source of Palaeolithic materials. Because the shale used in the artifacts was not uniform for each nodule in terms of its color, texture, and surface morphology, two types of shale were prepared for the experiment: sample A was characterized by finer grains, while sample B had coarse grains.

Figure 2 shows the microstructure of both samples obtained by transmission electron microscope (TEM) observation. While sample A is comprised of smaller grains having diameters of approximately $0.1-0.5 \mu \mathrm{m}$ without conspicuous cavities at the grain boundaries, sample B consists of larger grains having diameters of up to 3-4 $\mu \mathrm{m}$ with more inter-granular spaces.

Both samples contained a high content of well-crystallized $\alpha$-quartz, and their Xray diffraction patterns obtained prior to the experiments did not exhibit considerable differences. In order to avoid impurities and inclusions for the specimens, they were cut out of the inner homogeneous and uniform part of the nodules. In order to eliminate subjective human biases and variations, all shale samples were equally cut into approximately $15-\mathrm{mm}$ cubes using a diamond cutter. Four cubes were prepared for the test, two each for samples A and B. Each specimen was obtained from an approximately adjoining part so that the specimens would possess almost uniform characteristics. The experiment was conducted using a thermostatically controlled electric
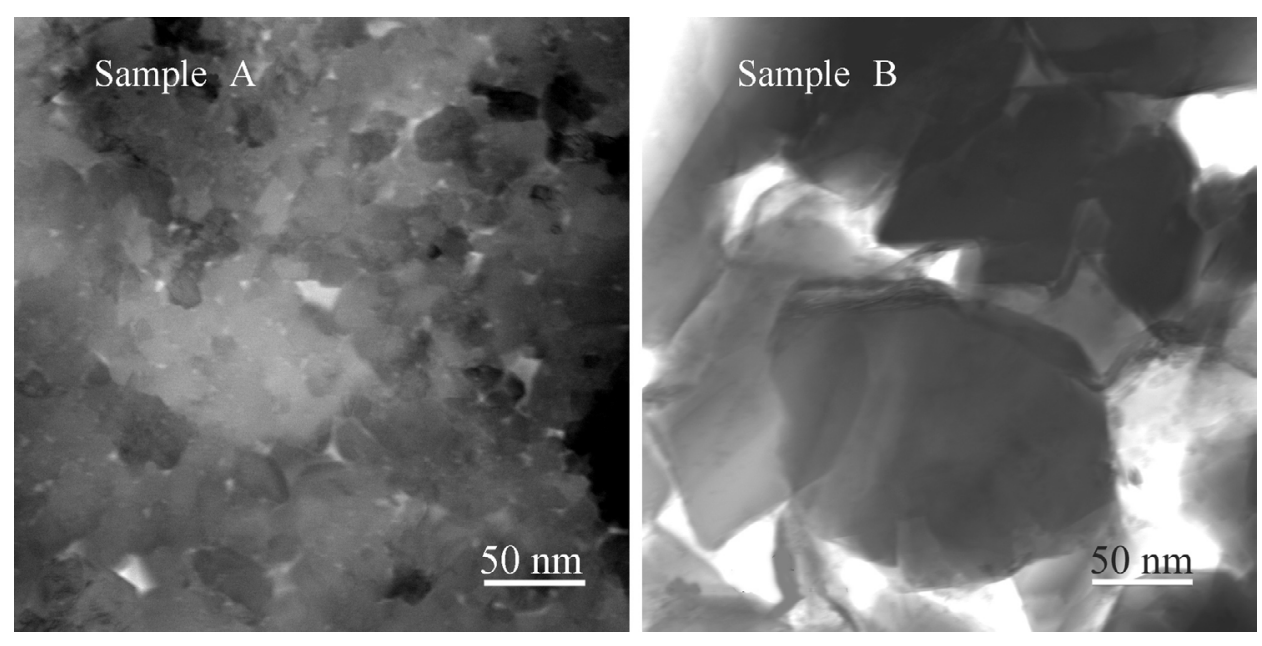

Fig. 2. Transmission electron micrographs of shale samples A and B. While sample A comprises smaller grains having diameters of approximately $0.1-0.5 \mu \mathrm{m}$ with fewer porosities, sample B comprises larger grains having diameters of up to $3-4 \mu \mathrm{m}$ with considerable pore spaces at grain boundaries. 
furnace. Two cubes of samples A and B were set at the center of the furnace for annealing, with the rest of the cubes unheated.

Since the purpose of this experiment is not to seek the optimal temperature for improving shale materials but to examine whether a desirable change actually occurs in them by heat treatment, various experimental frameworks described in preceding studies (Mandeville 1973; Purdy 1974; Purdy and Brooks 1971) were consulted to determine heating conditions. The temperature, time progress, and cooling condition employed in this study are as follows. To avoid explosion (Purdy 1974), the temperature was slowly increased to $350^{\circ} \mathrm{C}$ over $3 \mathrm{~h}$, i.e., the temperature was increased by $40^{\circ} \mathrm{C}$ every $15 \mathrm{~min}$ until the testing temperature was reached. Subsequently, the temperature was maintained at $350{ }^{\circ} \mathrm{C}$ for $10 \mathrm{~h}$; the samples were left in the furnace and allowed to cool until they reached an ambient temperature of approximately $25{ }^{\circ} \mathrm{C}$.

The mechanical properties of the rocks, such as flexural strength and Vickers microhardness, were measured before and after heating. Additionally, the minute surface morphology of each sample was investigated.

\section{Flexural Strength Test}

Flexural strength testing is an effective method for measuring the strength of very small, thin, and flat pieces. In this experimental setting, the standard testing method for ceramics was used: (1) ISO14704: fine ceramics (advanced ceramics, advanced technical ceramics), a test method for the flexural strength of monolithic ceramics at room temperature; and (2) ASTM C1161-02, the standard test method for the flexural strength of advanced ceramics at ambient temperature.

The strength of the rock materials was tested using the three-point flexure test. The specimen dimensions were changed slightly from those specified in the standards: the specimens had a width and thickness of $5.0 \mathrm{~mm}$ and $2.0 \mathrm{~mm}$, respectively, and the outer span of the support bearings was $10.0 \mathrm{~mm}$. The crosshead speed during loading was $0.5 \mathrm{~mm} / \mathrm{min}$, and the analysis was performed at room temperature $\left(25^{\circ} \mathrm{C}\right)$.

The samples were prepared in the following manner. First, the materials were cut from the 15-mm cubes using a diamond cutter into flat pieces having dimensions of $15 \mathrm{~mm} \times 15 \mathrm{~mm} \times 2 \mathrm{~mm}$ (width $\times$ length $\times$ thickness). Subsequently, these small plates were cut into pieces having a width and length of $5 \mathrm{~mm}$ and $15 \mathrm{~mm}$, respectively. Then, each piece was polished using waterproof abrasive papers to reduce the microcracks on the surface that occur during cutting since these cracks may cause stress concentration.

More than 15 pieces were prepared for the flexural test for each sample; however, due to the limited sample size and accidental chips that occurred during the cutting stages, it was impossible to use an identical number of pieces for all samples. Therefore, we attempted to use at least 15 pieces for each sample; the number of tests performed is specified in Table 1.

\section{Vickers Hardness Test}

For the quantitative measurement of rock hardness, the Vickers hardness test was used: (1) ASTM C1327-03 (standard test for the Vickers indentation hardness of advanced ceramics); (2) ISO/DIS 6507-1 (metallic materials-Vickers hardness test, part 1: Test 


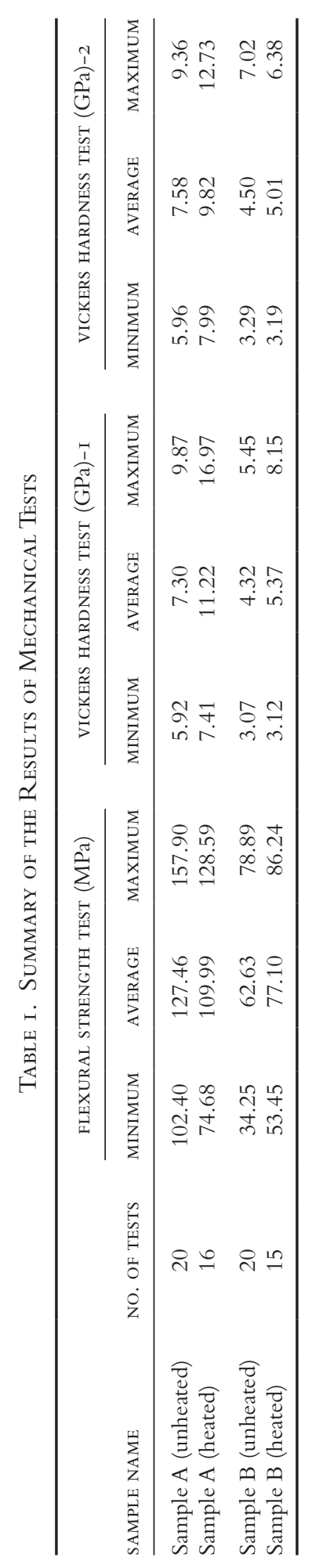


method); (3) JIS Z2244 (Vickers hardness test-Test method). The samples were fixed in resin to keep them stationary during the test. Subsequently, the specimen surface was polished using waterproof abrasive paper (\#500-\#1200) in several steps because the accuracy of the test depends on the smoothness of the specimen surface. Before the test, in order to observe the indentations clearly, the sample surfaces were coated with a $200-\mu$ m-thick layer of gold by vapor deposition.

The hardness measurement was performed using a hardness testing device (MVKH2, Akashi, Kanagawa, Japan) under ambient conditions. The applied load was 1.96 $\mathrm{N}$ and the loading time was $15 \mathrm{~s}$. Two hardness tests (tests 1 and 2) were carried out on each of the four samples, i.e., eight hardness tests were carried out in total. In each test, indentation measurements were performed 50 times to prevent the effect of variation in hardness due to the micropores and inclusions in the rock samples.

\section{Observations of Surface Morphologies through SEM}

Minute changes in the surface morphology were observed by scanning electron microscope (SEM). Thus far, SEM has been effectively applied for investigating the morphological changes in the surfaces of heat-treated rocks (Griffiths et al. 1987; Mandeville 1973; Olausson and Larsson 1982; Purdy 1974; Purdy and Brooks 1971; Rowney and White 1997; Schindler et al. 1982).

Prior to SEM observation, the samples were treated by gold vapor deposition to prevent charging, and observations were performed using a field emission SEM (FESEM; S-4700, Hitachi, Tokyo, Japan) at an accelerating voltage of 10-15 kV depending on the samples.

\section{RESULTS AND DISCUSSION}

\section{Flexural Strength}

In Figure 3, all data from the flexural strength test are plotted. Additionally, for the sake of clarity, the average strength of each sample is shown in Figure 4. As shown in Table 1 and Figures 3 and 4, the flexural strength of each sample was not consistent. With regard to sample A, the flexural strength roughly decreased after heating (Fig. 3). Specifically, while the original strength of sample A was $102.40-157.90 \mathrm{MPa}$, it decreased to 74.68-128.59 MPa after heating. Moreover, whereas the original average strength obtained from 20 strength tests was $127.46 \mathrm{MPa}$, after heating it was found to be $109.99 \mathrm{MPa}$ from 16 tests (Fig. 4). On the other hand, the strength of sample B increased with heating (Fig. 3). While the original strength was 34.25-78.89 MPa, it increased to 53.45-86.24 MPa after heating. The average value changed from 62.63 $\mathrm{MPa}$ before heating to $77.10 \mathrm{MPa}$ after heating (Fig. 4).

Since the first report on the improvement of flakeability by heating (Crabtree and Butler 1964), several researchers have performed both manual (Flenniken and Garrison 1975; Griffiths et al. 1987; Mandeville and Flenniken 1974; Patterson 1979) and mechanical (Domanski et al. 1994; Purdy 1974; Purdy and Brooks 1971; Schindler et al. 1982) tests on the flaking property of heated rocks. Among them, Purdy performed compressive strength tests and point tensile strength tests on Florida chert subjected to various heating conditions. In that work, both a decrease and increase in strength were observed in the examined samples (Purdy 1974). In addition, Domanski et al. (1994) conducted a detailed study in which mechanical properties such as the 

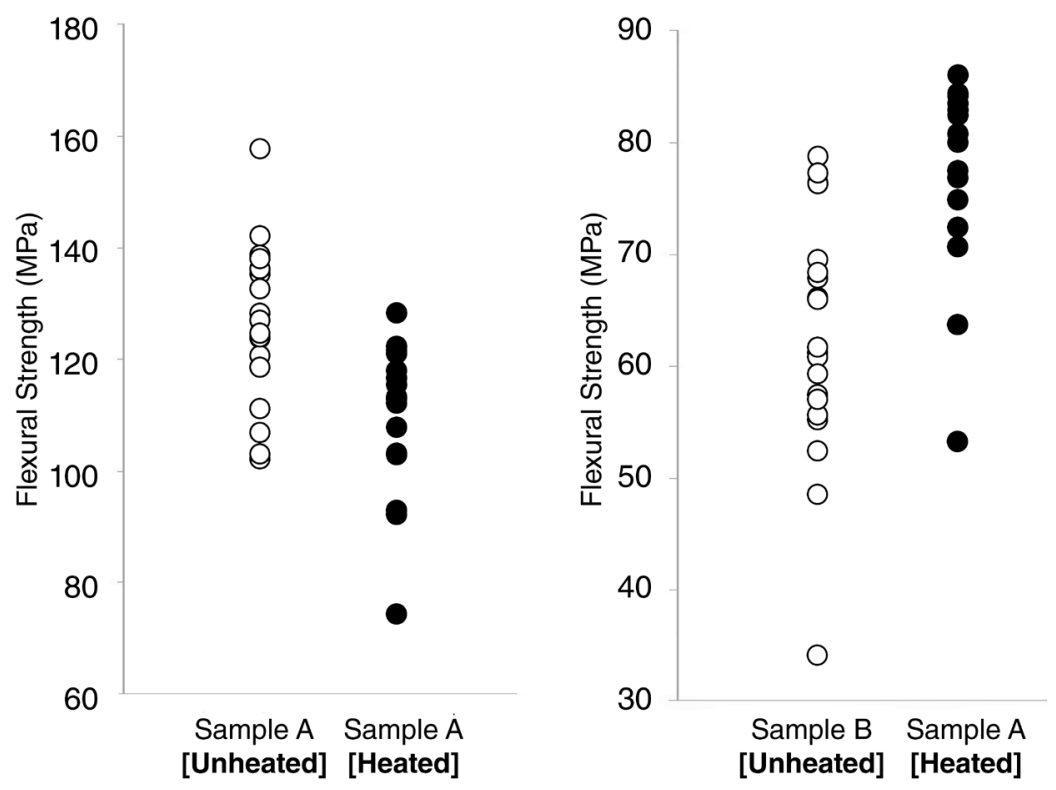

Fig. 3. Results of flexural strength test. While the strength of sample A decreased significantly, that of sample B increased after heating.
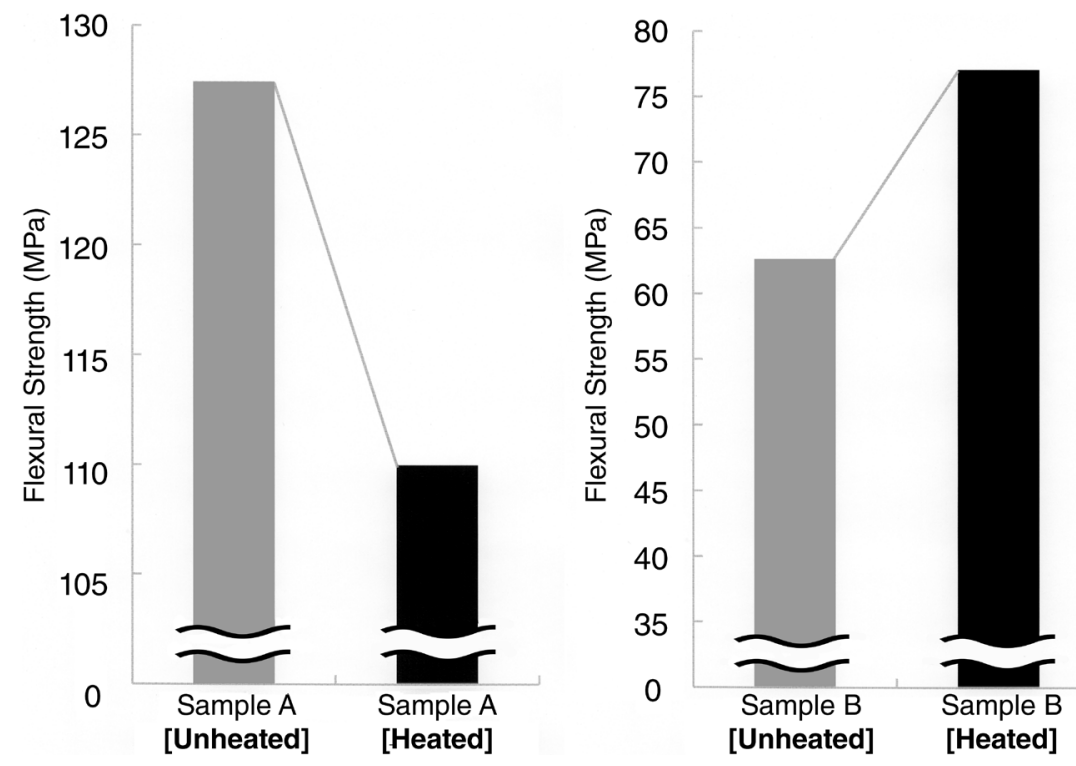

Fig. 4. Average values of flexural strength of each sample. While the strength of sample A reduced significantly, that of sample $B$ increased after heating. 
elastic response, compressive strength, tensile strength, and fracture toughness were measured before and after heating; the strength tests produced variable results.

Many researchers have reported that fine-grained and coarse-grained materials exhibit different responses to heat (Domanski et al. 1994; Mandeville 1973; Sollberger and Hester 1973). It may be assumed that the variability in the results of strength tests in this study was caused by the differences in temperature and durations of heating required for the transformation of each different material.

\section{Vickers Microhardness}

With regard to the results of the Vickers microhardness test, as shown in Table 1 and Figures 5 and 6 , the hardness value of both samples increased. Originally, sample A had an average hardness value of 7.3 and $7.58 \mathrm{GPa}$, while that of sample $\mathrm{B}$ was 4.32 and $4.5 \mathrm{GPa}$. After heating, that of sample $\mathrm{A}$ increased to 11.22 and $9.82 \mathrm{GPa}$ and that of sample B increased to 5.37 and $5.01 \mathrm{GPa}$. In particular, sample A exhibited a significant increase in hardness after heating. For instance, while the minimum values before heating were 5.92 and $5.96 \mathrm{GPa}$, they increased to 7.41 and $7.99 \mathrm{GPa}$ after heating. In addition, while the maximum values before heating were 9.87 and 9.36 GPa, they increased significantly to 16.97 and $12.73 \mathrm{GPa}$ after heating. Thus far, the flakeability of rock materials has attracted considerable attention by researchers; however, the result obtained here implies that in addition to the flaking properties, other mechanical factors, which might have influenced the completed tool performance such as edge quality, cutting capability, and tool durability can be altered by heat treatment.

\section{Surface Morphologies through SEM}

Figure 7 shows the surface morphology of shale before and after heating. As shown in the micrographs, both samples exhibited smoother surfaces to some extent after heating, particularly at high resolutions. With regard to sample A, although the original surface texture was rather fine-grained and quite flat, a much smoother surface with less inter-granular porosities was observed after heating. The surface of sample A appeared to be altered both at lower magnifications and at high resolution. On the other hand, although sample B appeared to be unchanged at lower magnifications, it was observed at high resolutions that each grain appeared to be fused mutually, and the grain shapes appeared to be obscured in the heated sample. Consequently, the surface of sample B appears to have less porosity at the grain boundaries and a relatively smoother surface at high resolution.

\section{CONCLUSIONS: THE MATERIAL ALTERATION OF SHALE BY HEATING}

In this preliminary study, shale materials were experimentally subjected to controlled heat treatment, and it was found that their mechanical properties and surface characterization can be altered. In order to interpret the obtained results, especially the alteration of the mechanical properties, data of the strength and hardness of the heated samples were compared with rocks obtained adjacent to the site, as well as actual archaeological artifacts. 

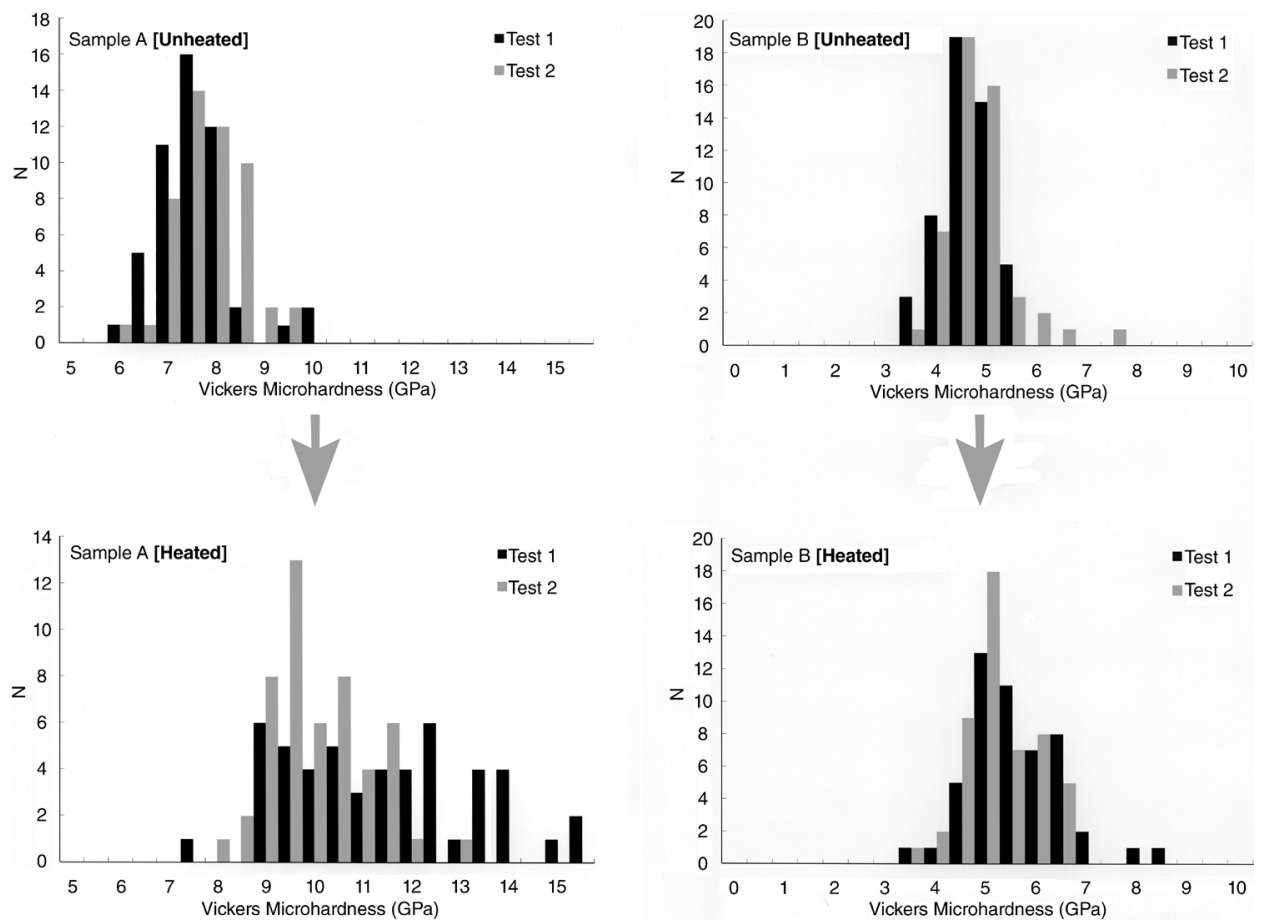

Fig. 5. Results of Vickers microhardness tests. The hardness values of both samples A and B increased after heating. In particular, that of sample A increased significantly after heating.
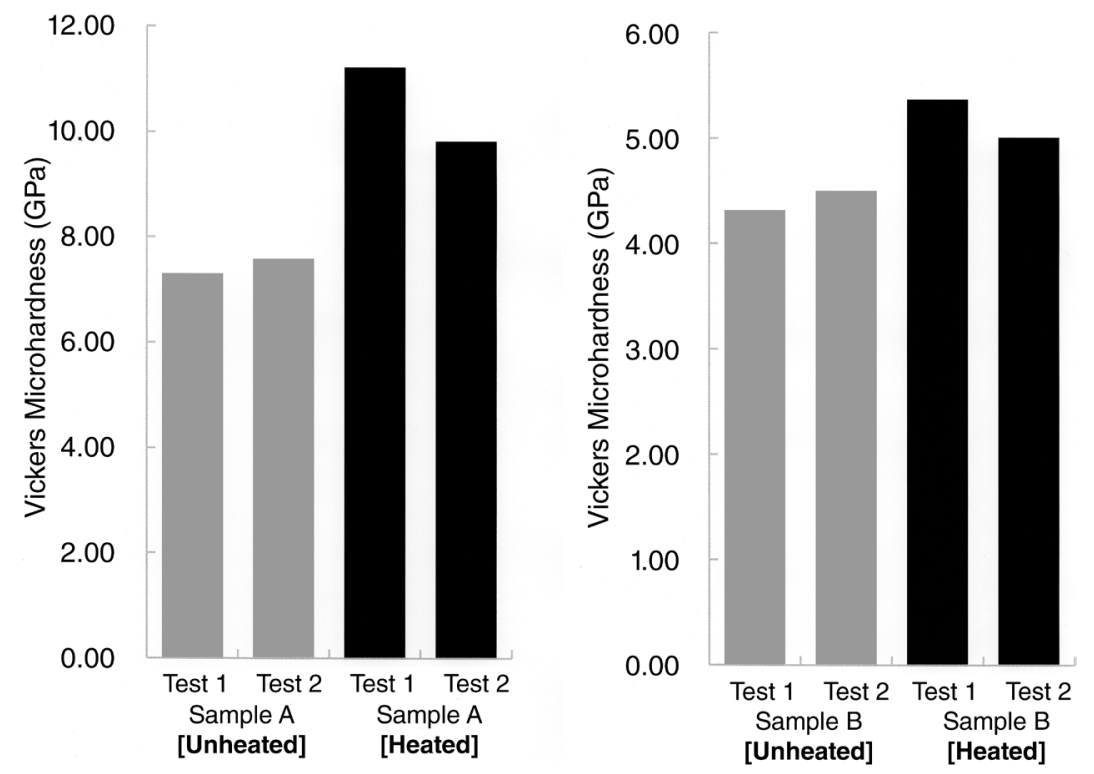

Fig. 6. To clarify the trends shown in Figure 5, the average values are indicated in the graphs. The hardness values of both samples increased; in particular, that of sample A increased significantly. 

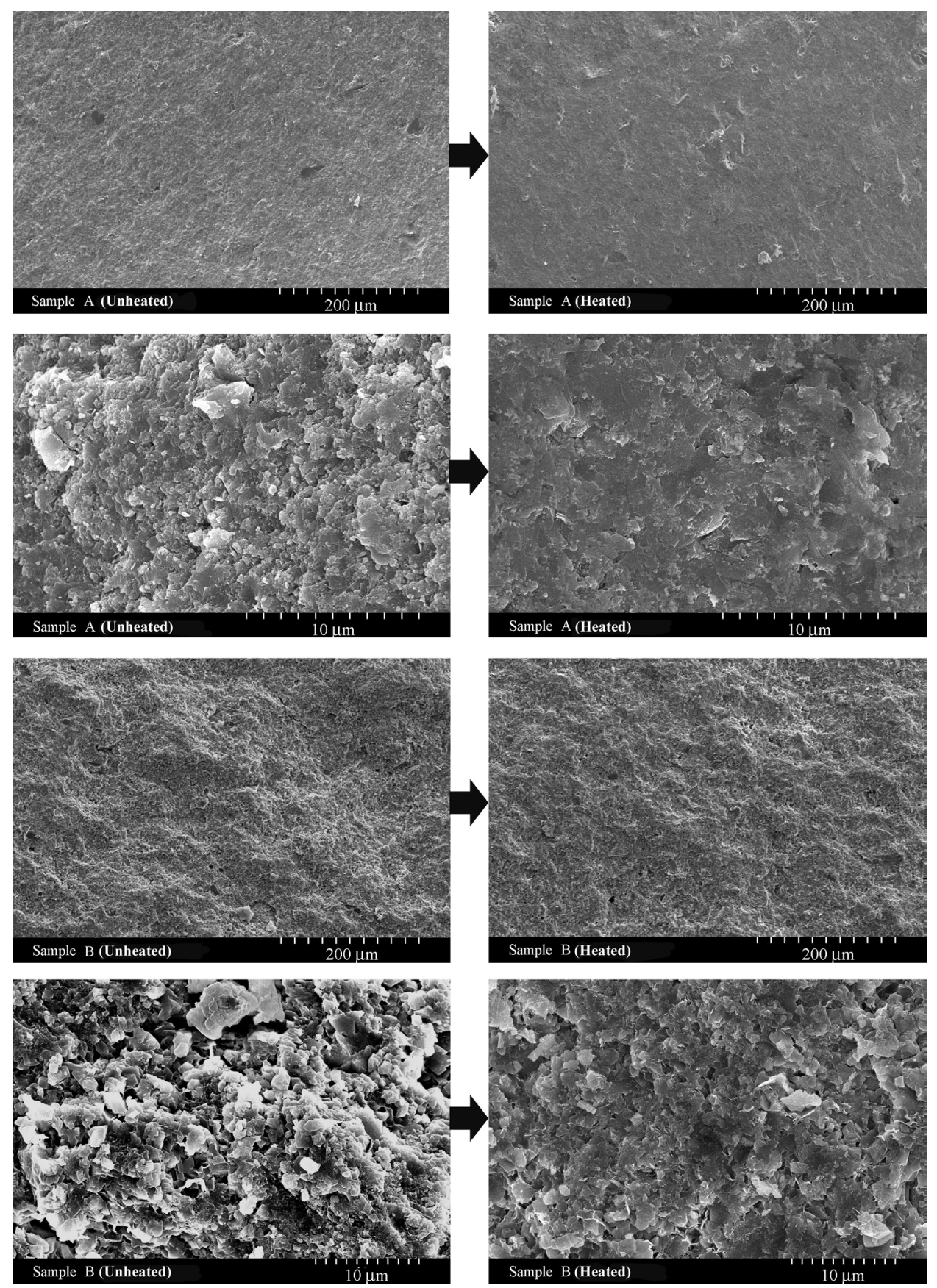

Fig. 7. SEM micrographs of each sample before and after heating. Smoother surfaces are observed, particularly at high resolutions, in both samples after heating. 


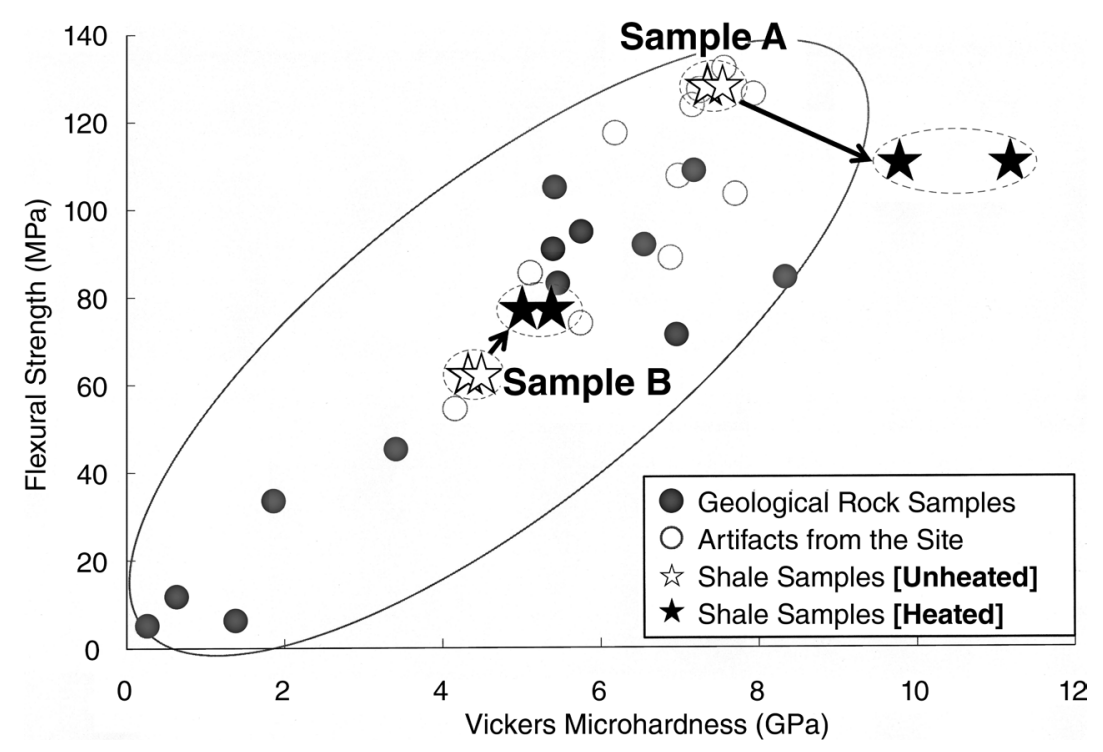

Fig. 8. Results of the mechanical properties of heated and unheated shale samples plotted with those of rocks available adjacent to the site and actual shale artifacts from the site. Sample A exhibited an improvement in terms of flakeability as well as hardness, which might have influenced the performance of completed tools.

In Figure 8, the average strength and hardness of the unheated and heated shale samples are plotted along with those of rocks available near the site. Additionally, data for shale artifacts obtained from the site that do not exhibit substantial heat effects are also plotted. As shown in this graph, the strength and hardness of geological rocks ranged from 5.1 to $127.3 \mathrm{MPa}$ and from 0.63 to $8.12 \mathrm{GPa}$, respectively. Among the rocks available adjacent to the site, materials with strength ranging from 54.5 to 132.1 $\mathrm{MPa}$ and hardness ranging from 4.16 to $7.94 \mathrm{GPa}$, were preferably selected for manufacturing tools.

As shown in this graph, because rock hardness has a close relationship to strength, materials with higher GPa generally also have increased strength. This tendency implies that certain hard materials that might have been suitable for manufacturing tools having specific characteristics such as durable edges, might not necessarily have been suitable for flaking in the manufacturing process. In other words, it might have been difficult to elaborately flake and shape hard materials having extremely high strength values.

However, heating shale materials, especially those having extremely high strength numbers, can reduce strength and improve workability, even with increasing hardness values. Moreover, from among the rocks available adjacent to the site, even those shale samples that originally had lower hardness values and strength exhibited increased mechanical properties after heating. Assuming that rock materials with increased flakeability and hardness were ideal for manufacturing tools due to their better flaking properties and better performance of the completed tool, controlled heating of shale may produce a desirable change in the materials - excessively high strength values can be reduced, resulting in better flakeability, and even incresed hardness can be realized. 
For a more detailed investigation of the relationship between rock alteration and manufacturing processes at the site, many shale samples having varied properties must be tested in the experiment. Moreover, a comprehensive understanding of the mechanism of alteration of rocks by heat treatment is required for a more thorough investigation of heating techniques used in prehistoric periods. In this regard, the alteration mechanism of rocks has been attributed to several causes, including: the microscopic impurities in the intercrystalline spaces that act as a flux during heat treatment and effectively weld the grains (Mandeville 1973; Purdy 1974; Purdy and Brooks 1971); recrystallization accompanied with water migration from the silica lattice and along grain boundaries into microfluid inclusions (Griffiths et al. 1987); the influence of the increased density of microfractures (Flenniken and Garrison 1975); recrystallization of silica resulting in reduced crystal size and an equigranular structure (Crabtree and Butler 1964; Domanski and Webb 1992), and transformation of the goethite component in jasper to hematite (Schindler et al. 1982).

To test the validity of these suppositions with regard to the shale materials examined in this study, further chemical and physical analyses should be performed. Furthermore, in order to obtain a detailed understanding of the heat treatment techniques used for tool manufacturing during the Palaeolithic age, functional and behavioral analyses in an archaeological context are also essential.

This study is only an initial step toward gaining a better understanding of human behavior with regard to the heat treatment of rocks in the Palaeolithic age. Nevertheless, the results obtained in this study imply that the use of heating processes, especially for hard shale, might have improved its mechanical properties in terms of flakeability and material performance. Therefore, if Paleolithic toolmakers were capable of heat treating rocks properly, it is reasonable to assume that they were able to improve the properties of the materials in terms of workability and material performance.

\section{ACKNOWLEDGMENTS}

This work was partially supported by a Grant-in-Aid for Scientific Research from the Japanese Ministry of Education, Culture, Sports, Science and Technology. Thanks are expressed to Professor Suzuki and Professor Komodori of Keio University for their generous assistance and support. Thanks are also due to Dr. Peter Bleed and Dr. Robert Elston for their valuable comments in the session of SAA 2007.

\section{REFERENCES CITED}

Crabtree, Don E., and B. Robert Butler

1964 Notes on experiment in flint knapping: 1- heat treatment of silica materials. Tebiwa 7 (1) : $1-6$.

Domanski, Marian, And John A. Webb

1992 Effect of heat treatment on siliceous rocks used in prehistoric lithic technology. Journal of Archaeological Science 19(6): 601-614.

Domanski, Marian, John A. Webb, and J. Boland

1994 Mechanical properties of stone artefact materials and the effect of heat treatment. Archaeometry 36(2): 177-208.

Flenniken, J. JefFrey, and Ervan G. Garrison

1975 Thermally altered novaculite and stone tool manufacturing techniques. Journal of Field Archaeology 2(1/2): 125-131. 
Griffiths, D. R., C. A. Bergman, C. J. Clayton, K. Ohnuma, G. V. Robins, and N. J. Seeley

1987 Experimental investigation of the heat treatment of flint, in Human Uses of Flint and Chert, Proceedings of the Fourth International Flint Symposium: 43-52, ed. G. de G. Sieveking, and M. H. Newcomer. Cambridge: Cambridge University Press.

Mandeville, Margaret D.

1973 A consideration of the thermal pretreatment of chert. Plains Anthropologist 18:177-202.

Mandeville, Margaret D., and J. JefFrey Flenniken

1974 A comparison of the flaking qualities of Nehawka chert before and after thermal pretreatment. Plains Anthropologist 19:146-148.

Olausson, Deborah Seitzer, and Lars Larsson

1982 Testing for the presence of thermal pretreatment of flint in the Mesolithic and Neolithic of Sweden. Journal of Archaeological Science 9(3):275-285.

Patterson, LeLAND W.

1979 Quantitative characteristics of debitage from heat treated chert. Plains Anthropologist 24:255259.

1995a Thermal damage of chert. Lithic Technology 20(1): 72-80.

1995 Intentional heat treatment: A reply to Rondeau. Lithic Technology 20(2) : 136-137.

Purdy, Barbara A.

1974 Investigations concerning the thermal alteration of silica minerals: An archaeological approach. Tebiwa 17(1):37-66.

Purdy, Barbara A., and H. K. Brooks

1971 Thermal alteration of silica minerals: An archeological approach. Science 173:322-325.

Rondeau, Michael F.

1995 Thermal damage does not equal heat treatment. Lithic Technology 20(2) : 135-136.

Rowney, Martin, and J. Peter White

1997 Detecting heat treatment on silcrete: Experiments with methods. Journal of Archaeological Science 24(7) : 649-657.

Schindler, Debra L., James W. Hatch, Conran A. Hay, and Richard C. Bradt

1982 Aboriginal thermal alteration of a central Pennsylvania jasper: Analytical and behavioral implications. American Antiquity 47(3): 526-544.

Siever, R.

1978 Shale, in McGraw-Hill Encyclopedia of the Geological Sciences: 755-756, ed. D. N. Lapedes. New York: McGraw-Hill.

Sollberger, J. B., and Thomas Roy Hester

1973 Some additional data on the thermal alteration of siliceous stone. Oklahoma Anthropological Society, Bulletin $21: 181-185$.

Taguchi, K., S. Shimoda, Y. Itihara, N. Imoto, R. Ishiwatari, A. Shimoyama, M. Akiyama, and N. SUZUKI

1986 Relationship of organic and inorganic diagenesis of Neogene tertiary rocks, Northeastern Japan, in Roles of organic matter in sediment diagenesis: Based on a symposium sponsored by the Society of Economic Paleontologists and Mineralogists, Special publication 38 (Society of Economic Paleontologists and Mineralogists) (ed. D. L. Gautier): 47-64.

YAALON, D. H.

1962 Mineral composition of the average shale. Clay Minerals Bulletin 5:31-36.

YoneKura, KaOru, and Yoshito Abe

2002 Ueno-A Site 1986-1998. Occasional Papers, vol. 13, The Department of Archaeology and Ethnology, Faculty of Letters, Keio University (in Japanese with English abstract).

Yonekura, Kaoru, Hiroyuki Hasegawa, Atsushi Hotta, and Tetsuya Suzuki

2008 A novel approach to studies of prehistoric exploitation of stone tool materials using material composition, surface morphology, microstructure and mechanical properties. Archaeometry 50(5): 727-746.

\section{ABSTRACT}

In order to obtain a better understanding of the intentional thermal alteration of Palaeolithic materials in the northeastern region of Japan, heating experiments were carried 
out on two types of shale samples. Mechanical properties such as strength and hardness as well as surface morphology were analyzed before and after heating. As a result, a functional change was observed in mechanical factors after heating. A hard shale sample comprising small grains exhibited a significant decrease in strength and noticeable increase in hardness after heating. On the other hand, shale comprising larger crystal grains exhibited an increase in both strength and hardness values. Moreover, smoother surfaces were observed through SEM analysis in both samples after heating. These results lead us to the conclusion that the heating process, especially in the case of harder shale with higher strength values, might have modified material properties such as flaking characteristics as well as functional attributes that are relevant to hardness. Keywords: thermal alteration, Japan, Palaeolithic, stone tools, flexural strength, microhardness, scanning electron microscopy. 